\title{
Review of Clinical Hypnosis in Dentistry
}

\author{
Asma Muzaffar* \\ Adjunct Assistant Professor, New York University, USA
}

*Corresponding author: Asma Muzaffar, Adjunct Assistant Professor, New York University, 30 Waterside Plaza, Apt 22H, NY, NY, 10010, USA

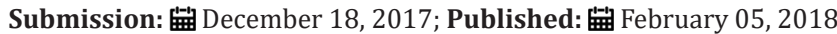

\section{Editorial}

Hypnosis is defined as a state of altered consciousness, which is confirmed by Neuro physiological changes and can be distinguished from meditative states and states of relaxation. The hypnotic state of consciousness is marked by an increase in alertness of inner awareness and decrease in ratings of external awareness [1]. A case study found change in the oscillations of brain during hypnosis [2]. During Hypnosis a re-organization in the composition of brain oscillations especially in Prefrontal Cortex and Right occipital EEG channels is observed. History has recorded hypnosis to be in use from the Shaman temples in India to Egyptian Temples, to Greek Temples. While the state of hypnosis was identified by Ibn Sina, the term hypnosis was coined by English Doctor James Baird in the year 1843 after Hypnos, the Greek God of Sleep. In the 1860, Civil War Surgeons used Hypnosis to amputate injured Soldiers and the American Psychological Association recognized Hypnosis as a valid procedure in the year 1960. In 2008, Research published in Journal Nature found evidence in using hypnosis for effectively treating IBS. Research done on dental pain as a randomized trial found a decrease in perception of pain and an increase in pain threshold in the randomized experimental subjects [3]. The pain threshold under self-hypnosis was higher $(57.1 \pm 17.1)$ than without hypnotic intervention $(39.5 \pm 11.8)(\mathrm{p}<.001)$. Pain was rated lower on the VAS with self-hypnosis $(4.0 \pm 3.8)$ than in the basal condition without self-hypnosis $(7.1 \pm 2.7)(\mathrm{p}<.001)$ [3]. Research done comparing the use of hypnotherapy in dentistry on treatment of dentin hyper sensitivity with other conventional therapies such as desensitizer and fluoridation did not show significant differences in success rates [4]. An important utilization of Hypnosis in Dentistry can be for the anxious, dental phobic patients. A study done mapping the functional changes of the brain in dental phobic patients found that the main effects of fear condition were found in the left amygdala and bilaterally in the Anterior Cingulate Cortex (ACC), insula and hippocampus. No amygdala activation was detected in healthy subjects in the two experimental conditions. During hypnosis Dental Phobic patients showed a significantly reduced activation in all of these areas. Reduced neural activity patterns were also found in the control group [5]. A prospective cohort study done on children aged 5 to 12 years with similar demographics, found the median modified Yale Pre Anxiety Scale and modified Objective Pain Score used to assess pain experience, significantly lower in Hypnosis group than Non Hypnosis group, illustrating the benefits of Hypnosis as an important adjunctive tool for optimal patient experience in the dentist's office [6].

\section{References}

1. Demertzi A, Vanhaudenhuyse A, Noirhomme Q Faymonville ME, Laureys (2015) Hypnosis modulates behavioural measures and subjective ratings about external and internal awareness. J Physiol Paris 109(4-6): 173-179.

2. Alexander AF, Andrew AF, Sakari Kallio, Anti Revonsuo (2007) Hypnosis induces a changed composition of brain oscillations in EEG: A case study. Contemporary Hypnosis 24(1): 3-18.

3. Wolf TG, Wolf D, Below D, D'Hoedt B, Willershausen B, et al. (2016) Effectiveness of self-hypnosis on the relief of experimental dental pain: a randomized trial. Int J Clin Exp Hypn 64(2): 187-199.

4. Eitner S, Bittner C, Wichmann M, Nickenig HJ, Sokol B (2010) Comparison of conventional therapies for dentin hypersensitivity versus medical hypnosis. Int J Clin Exp Hypn 58(4): 457-475.

5. Halsband U, Wolf TG (2015) Functional changes in brain activity after hypnosis in patients with dental phobia. J Physiol Paris 109(4-6): 131142.

6. Huet A, Lucas-Polomeni MM, Robert JC, Sixou JL, Wodey E (2011) Hypnosis and dental anesthesia in children: a prospective controlled study. Int J Clin Exp Hypn 59(4): 424-440. 
Creative Commons Attribution 4.0

International License

For possible submission use the below is the URL

Your subsequent submission with Crimson Publishers will attain the below benefits

- High-level peer review and editorial services

- Freely accessible online immediately upon publication

- Authors retain the copyright to their work

- Licensing it under a Creative Commons license

- Visibility through different online platforms

- Global attainment for your research

- Article availability in different formats (Pdf, E-pub, Full Text)

- Endless customer service

- Reasonable Membership services

- Reprints availability upon request

- One step article tracking system 